\title{
A Comparison of Health Care Use for Physician-Referred and Self-Referred Episodes of Outpatient Physical Therapy
}

\author{
Jane Pendergast, Stephanie A. Kliethermes, Janet K. Freburger, and \\ Pamela A. Duffy
}

Objective. To compare patient profiles and health care use for physician-referred and self-referred episodes of outpatient physical therapy (PT).

Data Source. Five years (2003-2007) of private health insurance claims data, from a Midwest insurer, on beneficiaries aged 18-64.

Study Design. Retrospective analyses of health care use of physician-referred $(N=45,210)$ and self-referred $(N=17,497)$ ambulatory PT episodes of care was conducted, adjusting for age, gender, diagnosis, case mix, and year.

Data Collection/Extraction. Physical therapy episodes began with the physical therapist initial evaluation and ended on the last date of service before 60 days of no further visits. Episodes were classified as physician-referred if the patient had a physician claim from a reasonable referral source in the 30 days before the start of PT.

Principal Findings. The self-referred group was slightly younger, but the two groups were very similar in regard to diagnosis and case mix. Self-referred episodes had fewer PT visits (86 percent of physician-referred) and lower allowable amounts $(\$ 0.87$ for every $\$ 1.00)$, after covariate adjustment, but did not differ in related health care utilization after PT.

Conclusions. Health care use during PT episodes was lower for those who selfreferred, after adjusting for key variables, but did not differ after the PT episode.

Key Words. Access to care, physical therapy, physician referral, direct access

Services delivered by physical therapists account for a significant portion of ambulatory care costs in the United States. In 2006, nearly 3.9 million Medicare beneficiaries received physical therapy (PT) services in ambulatory settings, accounting for about $\$ 3.1$ billion in payments to outpatient and office-based PT practices (Ciolek and Hwang 2008). Individuals not eligible for Medicare, particularly those with musculoskeletal conditions, also account for a significant portion of the ambulatory PT patient population (Freburger, Holmes, and Carey 2003) and ambulatory PT costs (Martin et al. 2008). In 
2007, Americans of all ages had over 164 million ambulatory visits for PT (AHRQ2009b,c).

Ambulatory PT services are commonly accessed through a physician referral, but in most U.S. states individuals may also access PT services through self-referral. Currently, PT practice acts in 46 states allow physical therapists to evaluate and treat patients in ambulatory settings without a physician referral (American Physical Therapy Association 2011). Of these, 17 allow unlimited direct access (i.e., evaluation and treatment without physician referral), whereas others impose some restrictions without a physician referral (e.g., limited to certain diagnoses such as the evaluation and treatment for children with developmental delays). Regardless of state practice acts, Medicare and some U.S. private health insurance plans require a physician referral for reimbursement of outpatient PT services. Self-referral, therefore, is primarily dictated by the provisions of patient health insurance coverage and is less likely in insurance plans where the physician serves as a gatekeeper for PT services.

Physician gatekeeping is not new; it was debated heavily in the 1980s and 1990s with the proliferation of health maintenance organizations (HMOs), and it is currently being revisited with the concept of the PatientCentered Medical Home (Mirabito and Berry 2010). The goals of physician gatekeeping are to deliver comprehensive and coordinated care, reduce ineffective and duplicative care, and ultimately, reduce health care costs. Studies of $\mathrm{HMO}$ and non-HMO plans generally indicate that quality of care is comparable and health care use is lower in HMO plans, but access to care is poorer and patients are less satisfied with their care (Miller and Luft 2002).

Consistent with the concept of physician gatekeeping, opponents of direct access to physical therapists argue that health care costs would increase due to overuse and/or inappropriate use of PT, continuity and coordination of care would suffer due to decreased physician-therapist communication, and serious pathologies would be missed because therapists lack the appropriate diagnostic skills. Opponents also argue that a physician examination is necessary to correctly diagnose and assess a patient's medical condition before

Address correspondence to Jane Pendergast, Ph.D., Director, Center for Public Health Statistics and Professor of Biostatistics, University of Iowa, Room C22K, 200 Hawkins Drive, Iowa City, IA; e-mail: jane-pendergast@uiowa.edu. Stephanie A. Kliethermes, M.S., is with the Department of Biostatistics, Center for Public Health Statistics, University of Iowa, Iowa City, IA. Janet K. Freburger, P.T., Ph.D., is with the Cecil G. Sheps Center for Health Services Research, Institute on Aging, Chapel Hill, NC. Pamela A. Duffy, P.T., Ph.D., O.C.S., C.P.C., is with the Public Health Program, Des Moines University, Des Moines, IA. 
initiation of PT, particularly for Medicare beneficiaries or others with comorbidities (Medicare Payment Advisory Commission 2004).

Proponents of direct access assert that physical therapists are appropriately educated to diagnose and treat conditions within the scope of PT practice and to screen for other medical conditions requiring a physician's assessment. They contend that direct access can improve the quality of care and clinical outcomes by decreasing patient wait times and health care costs (e.g., by eliminating unnecessary physician visits/tests, initiating treatment early before complications and chronicity begin), as well as ease the workload of overburdened primary care providers, thereby addressing the anticipated physician workforce shortage (APTA 2004). They also argue that the direct access model of care delivery has been successful in the military, where most individuals self-refer to PT for the evaluation and treatment of musculoskeletal conditions (Moore et al. 2005b).

While several research studies have explored the issue of direct access by examining the diagnostic skills of therapists relative to physicians (Overman et al. 1988; Springer et al. 2000; Childs et al. 2005; Moore et al. 2005a, b), few have examined issues related to health care use. Mitchell and de Lissovoy (1997) analyzed 4 years of Blue Cross-Blue Shield of Maryland health insurance claims data and found self-referred PT episodes of care were shorter, had fewer services, and were less costly than physician-referred episodes. As they did not control for illness severity, comorbidities, and other causes of persistent health care use, their findings may have been impacted by selection bias (e.g., patients with less severe problems and/or fewer interactions with the health care system may self-refer). Leemrijse, Swinkels, and Veenhof (2008) analyzed electronic health record data and reported fewer treatment sessions for self-referred versus physician-referred episodes of PT, though they also did not control for illness severity.

The primary objectives of our study were to compare patient profiles and health care use for physician-referred and self-referred episodes of PT on a large, non-Medicare, population with a common private health care insurance. We extend previous research by using methods to control for comorbidities/persistence of health care use during the previous year, and by examining PT use during the PT episode of care and all related health care use (i.e., related to problem for which PT was received) in three separate time frames: 30 days prior to, during, and 60 days following the PT episode. We examined related health care use to determine whether overall related health care use differs for self-referred versus physician-referred PTepisodes. 


\section{METHODS}

\section{Study Design and Data Source}

Cross-sectional analyses were conducted with 5 years (2003-2007) of de-identified, private, employer-based, health insurance claims data on approximately 1.3 million non-Medicare members in two states (approximately 91.2 million health and prescription claims). These two states were well suited for this study because both have allowed physical therapists to evaluate and treat without a physician referral for over 20 years (Iowa Code 2010; South Dakota Codified Laws 2010). Additionally, the payer does not require a physician referral for reimbursement of PT services. ${ }^{1}$

\section{Subjects and Database Construction}

The analyses were limited to members aged 18-64 years at the start of their PT evaluation who were continuously enrolled for at least 6 months before until 2 months after treatment. Physical therapist ${ }^{2}$ services were identified using both Current Procedural Terminology (CPT) codes (97001-97999) and provider specialty type. The PT claims for each member were aggregated to episodes of care by defining the start of the episode as the date of the PT initial evaluation $(\mathrm{CPT}=97001)$ preceded by 30 days with no PT claims. The ending date was that of the last PT claim before a 60-day window with no further PT claims. A second initial evaluation within the episode was considered a reevaluation, rather than the start of a new episode. All PT visits must have occurred in a physical therapist's office or in a hospital-based outpatient facility setting. If an individual had multiple PT episodes in this time frame, one was randomly selected for inclusion in the study.

The diagnosis associated with each PT episode was defined via the primary International Classification of Disease, 9th Revision, Clinical Modification (ICD-9-CM) diagnostic code recorded on the initial PT evaluation. The ICD-9-CM codes were categorized using the Agency for Healthcare Research and Quality's (AHRQ) Clinical Classification Software (CCS) (AHRQ 2009a). The CCS collapses ICD-9-CM codes into 285 clinically meaningful categories. As many of the CCS categories had very few responses, we further collapsed the categories into six broader diagnostic groups: arthritis and joint problems; neurological diagnoses; problems of the spine; sprains and strains; fractures and other traumatic joint disorders; and a V-code/miscellaneous group (Table A1). Doing this increased power when examining interactions 
by diagnosis, avoided problems associated with overfitting the data, and simplified data interpretation. PT episodes for fractures and traumatic joint disorders were excluded because individuals with such injuries typically see a physician and do not self-refer. Our final sample consisted of 62,707 PT episodes.

To classify PT episodes as physician-referred or self-referred, we generated a list of physician (MD or DO) specialty types that might reasonably refer patients to PT (Table A2). If there was any doubt, specialties were included so that physician referrals would not be misclassified as self-referrals. The episode was classified as physician-referred if one or more claims from any provider on the list occurred within 30 days prior to the initial PT evaluation (Mitchell and de Lissovoy 1997). Otherwise, the episode was classified as self-referred. Diagnoses reported on the physician claims were not considered because a patient might reasonably see a physician for one problem and request a PT referral at that time for an unrelated medical issue.

\section{Outcome Variables}

Health care use was measured by the number of PT visits and the total allowable amounts extracted from the claims data. The allowable amount, also known as the allowable fee, the maximum allowable fee, or the usual, customary, and reasonable fee (BlueCross BlueShield 2011) is the contractually agreed upon rate of reimbursement by the payer for services/ procedures delivered by the health care provider. Reimbursement for services at the allowable amount consequently becomes the de facto value of the services.

For office-based professional claims and non-date-spanned facility claims, a PT visit was determined by a unique service date on the claim. Therefore, there was only one visit per day. Less than 1 percent of outpatient facility claims were date-spanned (e.g., units of service across 30 days), and for these, a visit was defined as three units of service, representing approximately 45 minutes of PT time.

Total allowable amounts included amounts for provider visits (PT and non-PT), procedures, medical equipment, and prescription drugs with a supporting diagnosis code matching the CCS diagnostic category of the episode. This criterion eliminated claims that occurred in the window of care but were unrelated to the PT diagnosis. Total allowable amounts for services were assessed in four ways: (1) PT claims only during the PT episode; (2) all 
related non-PT claims in the PT episode; (3) all related claims in the 30 days prior to PT (excluding the referral visit); and (4) all related claims in the 60 days after PT. The first assessment examined only PT claims, while the latter three examined non-PT-related claims for the same underlying problem.

\section{Explanatory Variables}

The primary study variable of interest was referral status (physician or selfreferred) of the PT episode. The Adjusted Clinical Groups $\left(\mathrm{ACG}^{\odot}\right)$ software (The Johns Hopkins Bloomberg School of Public Health 2008) was used to adjust for potential differences in ambulatory case mix/morbidity burden in the two referral groups. The system uses the individual's age, gender, and medical claims history of the previous year to classify the individual into a single health status category reflecting persistence and severity of health care needs and use. Our study subjects were classified into 67 ACG categories (described in Table A3). A minimum of 6 months of data were used to classify an individual into an ACG category, but most had 12 months. Other explanatory variables were age, gender, CCS diagnostic group, and calendar year of initial PT visit.

\section{Statistical Analysis}

The unadjusted differences between the two referral groups on all variables were assessed using chi-square tests. Generalized linear models were used to compare health care use between the self-referred and physician-referred groups, after adjusting for explanatory variables. A negative binomial model was used to model the number of PT visits and linear regression was used to model the natural logarithms of the allowable amounts. The highest 1 percent of visits (more than 34 visits in an episode) and highest 1 percent of allowable amounts (e.g., more than $\$ 3,248$ for PT claims) were removed to eliminate the influence of uncharacteristically high values. All two-way interactions between referral group, treatment year, diagnosis group, gender, and age were considered candidate predictors in the models. To describe "average" allowable amounts in the log-normal regression models (e.g., men versus women or self- versus physician-referral groups), the least square means in the log scale were exponentiated to return to the original U.S. dollar scale (geometric mean). 


\section{Sensitivity Analyses}

Propensity score analyses were conducted to adjust for differences between patients in the two referral groups. The propensity scores were created using age, gender, group, year, ACG category, and place of service (facility or practitioner's office). Individuals in each group were matched on these scores using both a 1:1 and a 1:2 (self-referred: physician-referred) algorithm. In the 1:1 matching, 99.8 percent of self-referred individuals were matched to a physician-referred individual (97.8 percent to at least two decimal places). In the 1:2 matching, 85.3 percent of the self-referred individuals were matched $(84.2$ percent to two or more decimal places). Results were very similar to those using the generalized linear models described above and are not presented.

There was no appreciable difference when observations were weighted or not weighted by observed time (between 6 and 12 months) used to classify patients into ACG categories. The weighted analysis is presented.

Finally, we explored different time windows for determining selfreferred PT episodes (i.e., 30, 45, and 60 days without a physician claim). Differences in individual referral group designations were minimal for the three time lengths. Therefore, 30 days prior to the initial PT visit was chosen as the time window, which is consistent with previous research (Mitchell and de Lissovoy 1997).

\section{RESULTS}

\section{Comparison of Referral Groups}

Of the 62,707 PT episodes, 17,497 (28 percent) were classified as self-referred and 45,210 (72 percent) as physician-referred. Fifty-three percent of episodes occurred in an office and 47 percent in an outpatient facility. Summary statistics and univariate comparisons of key predictors between the self-referred and physician-referred groups are presented in Table 1. Due to the large sample size, some differences between the two groups are statistically significant $(p<.05)$ but are relatively small from a clinical perspective.

On average, the self-referred group was younger than the physicianreferred group (43.5 and 45.9 years, respectively). This difference was primarily driven by a larger proportion of individuals 55-64 years of age in the physician group and larger proportion of individuals 18-24 years of age in the self-referred group (Table 1). Overall, females accounted for a larger proportion of PT episodes of care (59 percent versus 41 percent), but the 
Table 1: Characteristics of Self-Referred and Physician-Referred Samples $(N=62,707)$

\begin{tabular}{lccc}
\hline & $\begin{array}{c}\text { Self-Referred } \\
(N=17,497)\end{array}$ & $\begin{array}{c}\text { Physician-Referred } \\
(N=45,210)\end{array}$ & \\
Explanatory Variables & $(\%)$ or Mean $(S D)$ & $(\%)$ or Mean $(S D)$ & $p$-Value \\
\hline Age (years) & $43.5(13.12)$ & $45.9(12.62)$ & $<.001$ \\
Age category & & & $<.001$ \\
18-24 & 12.1 & 8.5 & \\
$25-34$ & 14.6 & 11.9 & \\
35-44 & 20.2 & 19.0 & $<.001$ \\
$45-54$ & 29.1 & 30.4 & \\
55-64 & 24.0 & 30.3 & \\
Gender & & & \\
Male & 41.4 & 40.3 & \\
Female & 58.6 & 59.7 & \\
Diagnostic group & & & \\
Arthritis & 44.8 & 48.1 & \\
Spine & 33.4 & 30.7 & \\
Sprain/strain & 10.2 & 8.6 & \\
V-code/misc & 10.1 & 10.4 & \\
Neurological & 1.5 & 2.2 & \\
Year of initial visit & & & \\
2003 & 7.4 & 8.4 & \\
2004 & 17.8 & 19.1 & \\
2005 & 20.8 & 21.0 & \\
2006 & 25.8 & 25.3 & \\
2007 & 28.2 & 26.2 & \\
\hline
\end{tabular}

gender mix in the two referral groups was similar. Musculoskeletal conditions (arthritis, spine, sprain/strain) accounted for approximately 90 percent of PT episodes in both groups. The proportion of spine and sprain/strain PT episodes in the self-referred group was slightly higher, while that for arthritis was slightly lower. The distributions of patients classified into the 67 ACG categories were very similar between the two groups (Figure A1; Table A4). The largest difference was for the category 4010 (6-9 other Aggregated Diagnostic Group $[\mathrm{ADG}]^{3}$ combinations, age $35+, 0-1$ major ADGs). Thirteen percent of the self-referred group was classified in this category compared to 17 percent of the physician-referred group. The next largest difference (two percentage points) was for the category 0400 (Acute Major), and all other categories differed by less than two percentage points.

The number of PT episodes increased across years for both referral groups, reflecting both an overall increase in use of PT services and an increasing number of insured members over time. The low percentage of 
episodes in 2003 was due to the inclusion criteria for establishing the ACG category (i.e., at least 6 months of health care claims before the initial PT visit).

\section{Unadjusted Relationship between Referral Group and Health Care Use}

Unadjusted health care use was greater for the physician-referred group than the self-referred group before and during the PT episode, but not in the 60 days afterward (Table 2). On average, the physician-referred PT episodes had one more PT visit than self-referred episodes (7.0 versus 5.9). Of those classified as physician-referred, 43.0 percent had at least one related claim before PT started (excluding the referral visit), compared with 20.2 percent in the self-referral group. During the PT episode, 56.3 percent of the physicianreferred and 40.5 percent of the self-referred had at least one related claim in addition to those for PT. In the 60 days afterward, the proportion of subjects with additional related claims drops to 25.1 percent in the physician-referred group and returns to pre-PT levels (19.4 percent) in the self-referred group.

Due to the highly skewed nature of the data, both allowable amounts (U.S.\$) and $\log _{\mathrm{e}}$ allowable amounts are presented. During the PT episode, PT claims had an average allowable amount of $\$ 420$ for the physician-referred group compared to $\$ 347$ for the self-referred group (Table 2). Among those who had related (non-PT) claims during the PTepisode, the average allowable amounts in the two referral groups differed by $\$ 21.89$ ( $\$ 126.47$ physician- versus $\$ 104.58$ self-referred) $(p<.001)$. Of those who had at least one related claim in the 30 days before PT, the average allowable amount for the physician-referred group was $\$ 15.98$ higher than for the self-referred group $(p<.001)$. In the 60 days after the PT episode, there was no statistical difference in allowable amounts between the two referral groups.

\section{Covariate-Adjusted Relationship between Referral Group and Health Care Use}

The adjusted rate of PT visits per PT episode of care for self-referred patients was significantly lower than for physician-referred patients (Table 3). The magnitude of the difference depended on the gender, diagnostic group, and calendar year. Overall, those who self-referred had 86 percent as many visits per episode as those who were physician-referred.

Although the adjusted rate ratio of number of PT visits (self- versus physician-referred) was modified by other patient characteristics, it consistently ranged from 0.80 to 0.90 (Table 3 ). The rate ratio was lower for males $(0.85)$ than females (0.88) indicating less of a difference between referral groups for 
Table 2: Summary Statistics on Health Care Use of Self-Referred and Physician-Referred Groups

\begin{tabular}{|c|c|c|c|}
\hline Outcome Variables & $\begin{array}{c}\text { Self-Referred } \\
\text { Mean (SD) } \\
\text { Median [IQR] } \\
N \\
\end{array}$ & $\begin{array}{c}\text { Physician-Referred } \\
\text { Mean (SD) } \\
\text { Median [IQR] } \\
N\end{array}$ & $p$-Value \\
\hline $\begin{array}{l}\text { Total PT visits for } \\
\text { PTepisode }(N=62,117)\end{array}$ & $\begin{array}{l}5.90(5.55) \\
4[6] \\
N=17,362\end{array}$ & $\begin{array}{l}7.00(6.09) \\
5[8] \\
N=44,755\end{array}$ & $<.001$ \\
\hline Allowable Amounts & $\begin{array}{c}\text { Geometric Mean } \\
\text { Mean }(S D) \\
\text { Median }[I Q R] \\
N\end{array}$ & $\begin{array}{c}\text { Geometric Mean } \\
\text { Mean (SD) } \\
\text { Median [IQR] } \\
N\end{array}$ & \\
\hline $\begin{array}{l}\text { PTepisode PT } \\
\text { claims only } \\
(N=62,079)\end{array}$ & $\begin{array}{l}\$ 347.23 \\
\$ 503.12(\$ 478.18) \\
\$ 341.76[\$ 476.62] \\
N=17,385\end{array}$ & $\begin{array}{l}\$ 419.89 \\
\$ 605.49(\$ 549.61) \\
\$ 427[\$ 575.59] \\
N=44,694\end{array}$ & $<.001$ \\
\hline $\begin{array}{l}\text { PTepisode other } \\
\text { related claims } \\
(N=32,514 ; 52.4 \%)\end{array}$ & $\begin{array}{l}\$ 104.58 \\
\$ 526.26(\$ 1448.95) \\
\$ 96.54[\$ 288.07] \\
N=7,080 ; 40.5 \%\end{array}$ & $\begin{array}{l}\$ 126.47 \\
\$ 678.64(\$ 1744.11) \\
\$ 118.75[\$ 373.25] \\
N=25,434 ; 56.3 \%\end{array}$ & $<.001$ \\
\hline $\begin{array}{l}30 \text { days prior to PTepisode } \\
(N=22,980 ; 37.0 \%)\end{array}$ & $\begin{array}{l}\$ 56.26 \\
\$ 369.32(\$ 1249.31) \\
\$ 50.00[\$ 141.56] \\
N=3,538 ; 20.2 \%\end{array}$ & $\begin{array}{l}\$ 72.24 \\
\$ 451.96(\$ 1362.37) \\
\$ 69[183.08] \\
N=19,442 ; 43.0 \%\end{array}$ & $<.001$ \\
\hline $\begin{array}{c}60 \text { days after PTepisode } \\
(N=14,712 ; 23.7 \%)\end{array}$ & $\begin{array}{l}\$ 64.72 \\
\$ 356.12(\$ 1056.64) \\
\$ 59.64[\$ 177.0] \\
N=3,389 ; 19.4 \%\end{array}$ & $\begin{array}{l}\$ 62.18 \\
\$ 324.76(\$ 1022.17) \\
\$ 58.34[\$ 162.88] \\
N=11,323 ; 25.1 \%\end{array}$ & .127 \\
\hline Log (Allowable Amounts in \$) & $\begin{array}{c}\text { Mean }(S D) \\
\text { Median [IQR] }\end{array}$ & $\begin{array}{c}\text { Mean }(S D) \\
\text { Median [IQR] }\end{array}$ & \\
\hline $\begin{array}{l}\text { PTepisode PT } \\
\text { claims only }(N=62,079)\end{array}$ & $\begin{array}{l}5.85(0.860) \\
5.83[1.31]\end{array}$ & $\begin{array}{l}6.04(0.877) \\
6.06[1.29]\end{array}$ & $<.001$ \\
\hline $\begin{array}{l}\text { PTepisode other related } \\
\text { claims }(N=32,514)\end{array}$ & $\begin{array}{l}4.65(1.78) \\
4.57[2.38]\end{array}$ & $\begin{array}{l}4.84(1.85) \\
4.78[2.51]\end{array}$ & $<.001$ \\
\hline $\begin{array}{l}30 \text { days prior to } \\
\text { PTepisode }(N=22,980)\end{array}$ & $\begin{array}{l}4.03(1.75) \\
3.91[2.45]\end{array}$ & $\begin{array}{l}4.28(1.81) \\
4.23[2.52]\end{array}$ & $<.001$ \\
\hline $\begin{array}{l}60 \text { days after PTepisode } \\
(N=14,712)\end{array}$ & $\begin{array}{l}4.17(1.77) \\
4.09[2.55]\end{array}$ & $\begin{array}{l}4.13(1.71) \\
4.07[2.43]\end{array}$ & .245 \\
\hline
\end{tabular}

Notes. The highest $1 \%$ of visits and highest $1 \%$ of allowable amounts were excluded as outliers. PT, physical therapy. 


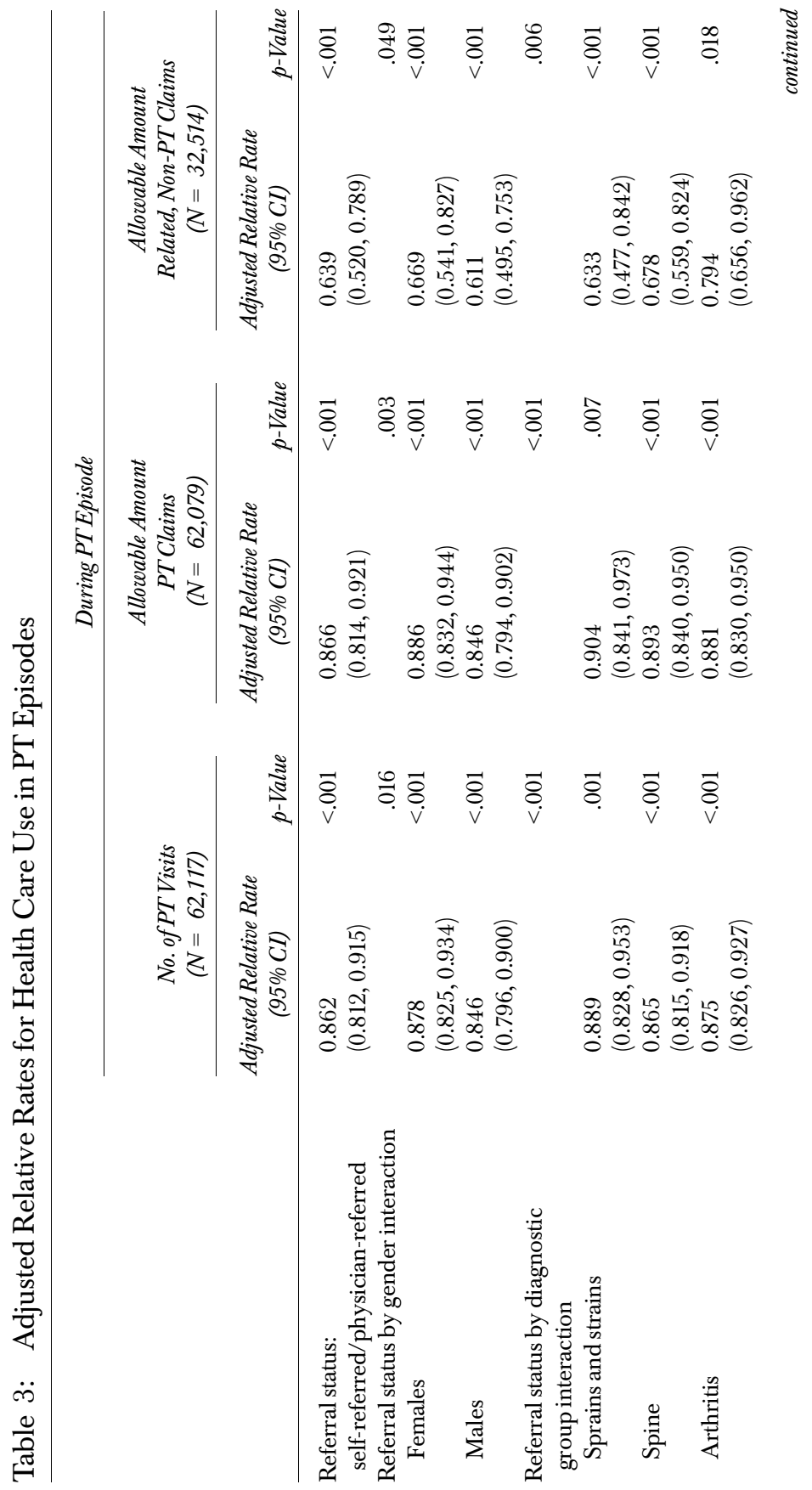




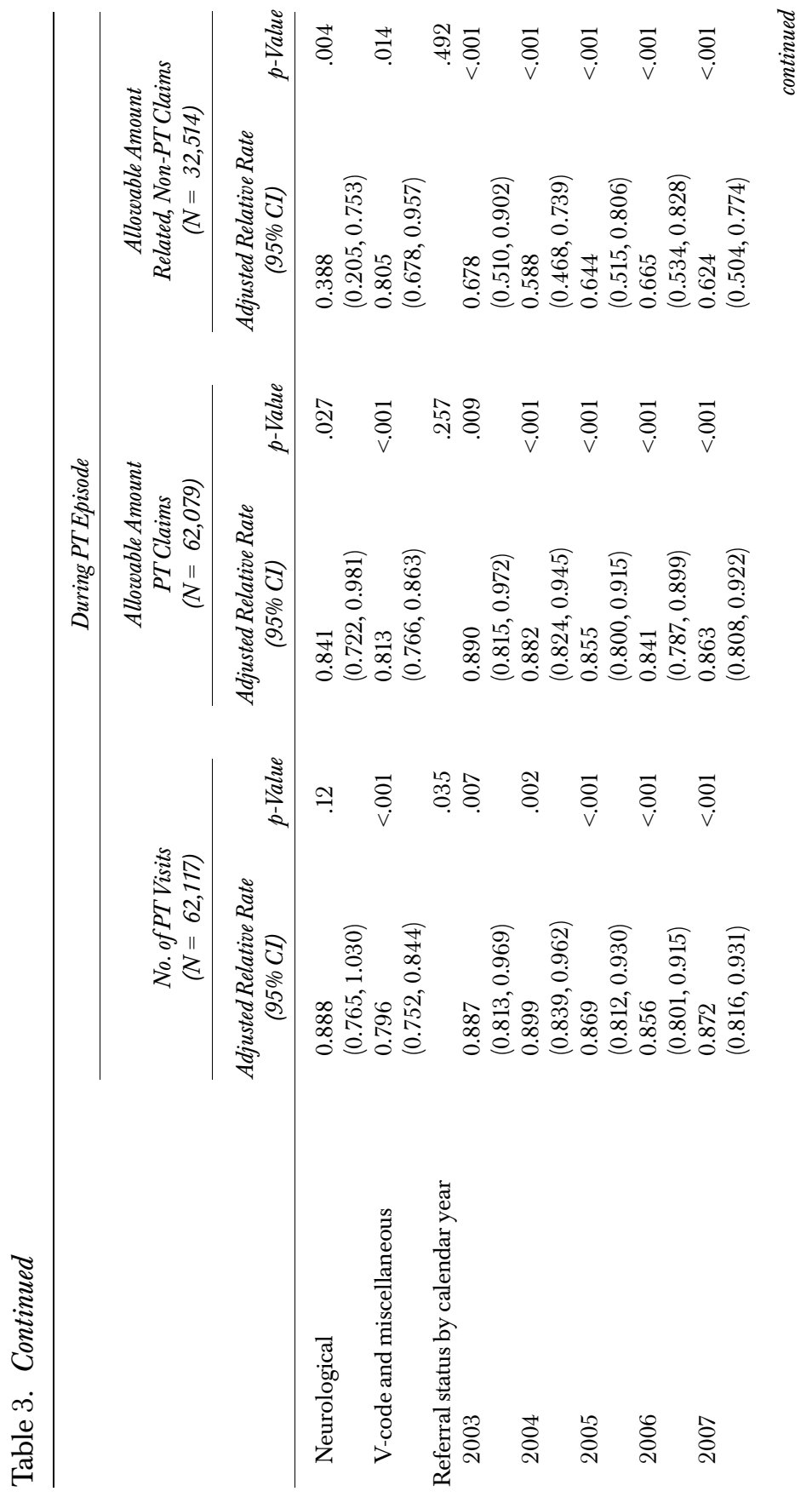




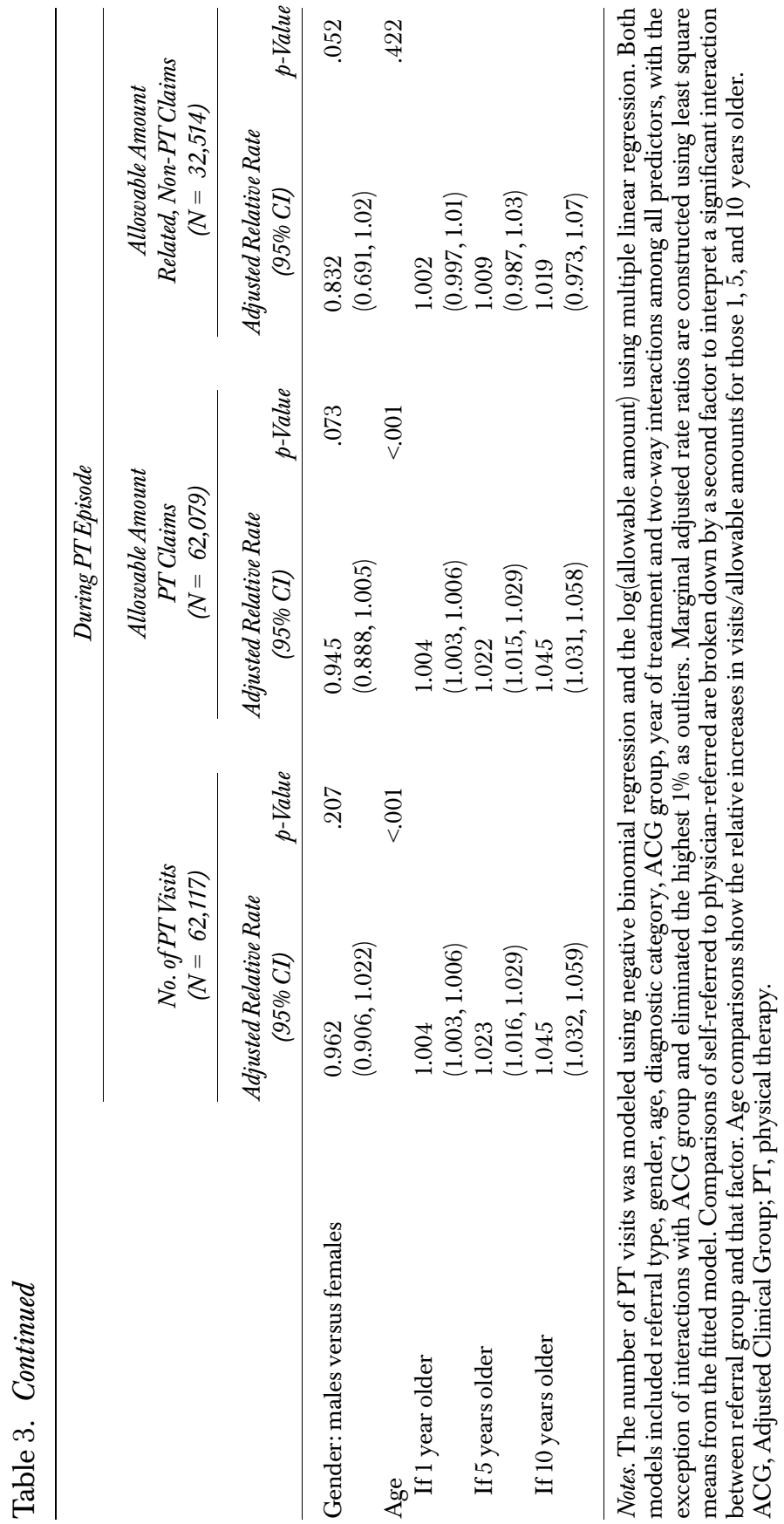


females than males, controlling for other covariates. Likewise, the adjusted rate ratios in the five diagnostic groups ranged from a low of 0.80 for $\mathrm{V}$-Code/ miscellaneous to 0.89 for sprains/strains, and ranged from 0.86 to 0.90 across the study years. Estimated PT visits per episode differed by gender and referral group, $(5.58[\mathrm{M}]$ versus $5.66[\mathrm{~F}]$ in physician-referred, $4.87[\mathrm{M}]$ versus 5.13 $[\mathrm{F}]$ in self-referred) and ranged from 4.71 (spine) to 5.93 (sprain/strain), after controlling for other predictors. As would be expected, older individuals had more PT visits (4.5 percent more for each 10 year increase in age). There was also an increase in the average number of visits for both referral groups over time, with a slightly larger ( 0.5 visits) increase in the physician-referred group (Tables A5 and A6).

In the 30 days prior to PT, and excluding the referral visit, the only referral group difference seen in health care use (log allowable amount) was its interaction with gender (Tables 4, A7 and A8). The estimated adjusted average allowable amount of self-referrals was $\$ 161.42$ for males and $\$ 140.29$ for females, compared to $\$ 205.20$ (males) and $\$ 158.14$ (females) in the physicianreferred group.

During the PT episode, the results for adjusted allowable amount of PT claims was consistent with that for number of PT visits (Tables 3, A9 and A10) and is not described further.

The adjusted relative rate of related, non-PT claims during the PT episode showed a stronger difference between the two-referral groups, with $\$ 0.64$ spent on average in the self-referred group for every $\$ 1.00$ spent in the physician-referred group (Tables 3, A11 and A12). The gender by referral group interaction was still significant, but less so $(p=.049)$. On average, the adjusted difference between males and females was trivial in the self-referred group ( $\$ 172.78$ females; $\$ 173.76$ males), but more substantial in the physicianreferred (\$242.86 females; \$267.44 males). If the PT claims are included in the total, the situation reverses, with a smaller difference in the physician-referred group ( $\$ 12.75$ versus $\$ 25.70$ ), reflecting greater use of PT services by women. Related, non-PT claims also differed between referral groups across diagnosis, with rate ratios ranging from 0.39 (neurological; averages of $\$ 236.13$ versus $\$ 572.32)$ ) to 0.81 (V-code/misc.; $\$ 57.60$ versus $\$ 67.24)$, and intermediate values of 0.63 (sprains/strains; $\$ 254.14$ versus \$377.21), 0.68 (spine; $\$ 284.52$ versus $\$ 394.30$ ), and 0.79 (arthritis; $\$ 158.76$ versus $\$ 187.90$ ).

There were no significant differences found between referral groups in the 60 days after the PTepisode, after adjusting for other covariates (Tables 4, A13 and A14). 
Table 4: Adjusted Relative Rates for Health Care Use Thirty Days Before and Sixty Days after PT Episode

\begin{tabular}{|c|c|c|c|c|}
\hline & \multirow{2}{*}{\multicolumn{2}{|c|}{$\begin{array}{c}30 \text { Days before } P T \\
\text { Allowable Amount Related, } \\
\text { Non-PT Claims } \\
(N=22,980)\end{array}$}} & \multirow{2}{*}{\multicolumn{2}{|c|}{$\begin{array}{c}60 \text { Days after } P T \\
\text { Allowable Amount Related, } \\
\text { Non-PT Claims } \\
(N=14,712)\end{array}$}} \\
\hline & & & & \\
\hline & $\begin{array}{l}\text { Adjusted Relative } \\
\text { Rate }(95 \% \text { CI) }\end{array}$ & $p$-Value & $\begin{array}{l}\text { Adjusted Relative } \\
\text { Rate (95\% CI) }\end{array}$ & $p$-Value \\
\hline $\begin{array}{l}\text { Referral status: } \\
\text { self-referred/physician-referred }\end{array}$ & $\begin{array}{l}0.913 \\
(0.696,1.20)\end{array}$ & .126 & $\begin{array}{l}0.862 \\
(0.604,1.13)\end{array}$ & .230 \\
\hline $\begin{array}{l}\text { Referral status by gender } \\
\text { interaction }\end{array}$ & & .034 & & .376 \\
\hline Females & $\begin{array}{l}0.970 \\
(0.734,1.28)\end{array}$ & .830 & $\begin{array}{l}0.803 \\
(0.583,1.11)\end{array}$ & .179 \\
\hline Males & $\begin{array}{l}0.860 \\
(0.653,1.13)\end{array}$ & .284 & $\begin{array}{l}0.849 \\
(0.618,1.17)\end{array}$ & .312 \\
\hline $\begin{array}{l}\text { Referral status by diagnostic } \\
\text { group interaction }\end{array}$ & & .125 & & .596 \\
\hline Sprains and strains & $\begin{array}{l}1.146 \\
(0.804,1.63)\end{array}$ & .450 & $\begin{array}{l}0.770 \\
(0.470,1.26)\end{array}$ & .296 \\
\hline Spine & $\begin{array}{l}0.846 \\
(0.668,1.07)\end{array}$ & .166 & $\begin{array}{l}0.849 \\
(0.643,1.12)\end{array}$ & .249 \\
\hline Arthritis & $\begin{array}{l}0.867 \\
(0.677,1.11)\end{array}$ & .256 & $\begin{array}{l}0.995 \\
(0.749,1.32)\end{array}$ & .973 \\
\hline Neurological & $\begin{array}{l}0.768 \\
(0.321,1.84)\end{array}$ & .553 & $\begin{array}{l}0.645 \\
(0.237,1.76)\end{array}$ & .391 \\
\hline V-code and miscellaneous & $\begin{array}{l}0.985 \\
(0.784,1.22)\end{array}$ & .892 & $\begin{array}{l}0.914 \\
(0.714,1.17)\end{array}$ & .477 \\
\hline Referral status by calendar year & & .559 & & .272 \\
\hline 2003 & $\begin{array}{l}0.940 \\
(0.651,1.36)\end{array}$ & .743 & $\begin{array}{l}0.814 \\
(0.540,1.23)\end{array}$ & .325 \\
\hline 2004 & $\begin{array}{l}1.00 \\
(0.743,1.35)\end{array}$ & .991 & $\begin{array}{l}0.721 \\
(0.511,1.02)\end{array}$ & .062 \\
\hline 2005 & $\begin{array}{l}0.864 \\
(0.643,1.16)\end{array}$ & .332 & $\begin{array}{l}0.863 \\
(0.619,1.20)\end{array}$ & .385 \\
\hline 2006 & $\begin{array}{l}0.894 \\
(0.671,1.19)\end{array}$ & .445 & $\begin{array}{l}0.902 \\
(0.651,1.25)\end{array}$ & .538 \\
\hline 2007 & $\begin{array}{l}0.874 \\
(0.662,1.15)\end{array}$ & .341 & $\begin{array}{l}0.839 \\
(0.606,1.16)\end{array}$ & .287 \\
\hline Gender: males versus females & $\begin{array}{l}0.728 \\
(0.595,0.892)\end{array}$ & .002 & $\begin{array}{l}0.939 \\
(0.711,1.24)\end{array}$ & .659 \\
\hline Age & & .543 & & .514 \\
\hline If 1 year older & $\begin{array}{l}0.998 \\
(0.993,1.001)\end{array}$ & & $\begin{array}{l}0.998 \\
(0.991,1.001)\end{array}$ & \\
\hline
\end{tabular}


Table 4. Continued

\begin{tabular}{|c|c|c|c|c|}
\hline & \multicolumn{2}{|c|}{30 Days before $P T$} & \multicolumn{2}{|c|}{60 Days after $P T$} \\
\hline & $\begin{array}{r}\text { Allowable Amou } \\
\text { Non-PT C } \\
(N=22,\end{array}$ & $\begin{array}{l}\text { Related, } \\
\text { as } \\
\text { ) }\end{array}$ & $\begin{array}{r}\text { Allowable Amou } \\
\text { Non-PTCl} \\
(N=14,\end{array}$ & $\begin{array}{l}\text { Related, } \\
\text { is } \\
\text { ) }\end{array}$ \\
\hline & $\begin{array}{c}\text { Adjusted Relative } \\
\text { Rate }(95 \% \text { CI) }\end{array}$ & $p$-Value & $\begin{array}{c}\text { Adjusted Relative } \\
\text { Rate }(95 \% \text { CI) }\end{array}$ & $p$-Value \\
\hline If 5 years older & $\begin{array}{l}0.992 \\
(0.966,1.02)\end{array}$ & & $\begin{array}{l}0.988 \\
(0.954,1.02)\end{array}$ & \\
\hline If 10 years older & $\begin{array}{l}0.984 \\
(0.933,1.04)\end{array}$ & & $\begin{array}{l}0.977 \\
(0.910,1.05)\end{array}$ & \\
\hline
\end{tabular}

Notes. The $\log$ (allowable amount) using multiple linear regression with referral type, gender, age, diagnostic category, ACG group, year of treatment, and two-way interactions among all predictors, with the exception of interactions with ACG group. The highest $1 \%$ were eliminated as outliers. Marginal adjusted rate ratios are constructed using least square means from the fitted model. Comparisons of self-referred to physician-referred are broken down by a second factor to interpret a significant interaction between referral group and that factor. Age comparisons show the relative increases in visits/allowable amounts for those 1,5 , and 10 years older.

ACG, Adjusted Clinical Group; PT, physical therapy.

\section{DISCUSSION}

Using a claims-based approach and controlling for general comorbidities and previous health care use, we found that self-referred episodes of outpatient PT had fewer visits than physician-referred episodes. We also found that total allowable amounts for PT claims and related non-PT claims during the PTepisode were lower for self-referred versus physician-referred episodes of care.

The pattern of less utilization during the PT episode in the self-referred group was maintained across gender, age, and diagnostic group, although there was some variation in the magnitude of the difference across these subgroups. One consistent finding was that rate ratios (self-referred/physicianreferred) for males were significantly less than those for females, regardless of whether the allowable amount was higher for men (e.g., related non-PT claims) or lower (PT claims). For men, the difference in health care use between self-referred and physician-referred episodes was always stronger than the difference for females. The reasons for this finding are unclear, but they may be related to the manner in which males interact/communicate with physical therapists and physicians.

Our findings regarding visits are consistent with others who have compared health care use among self-referred and physician-referred PT episodes 
(Mitchell and de Lissovoy 1997; Leemrijse, Swinkels, and Veenhof 2008). Total visits for self-referred episodes of outpatient PT were, on average, 62.2 percent of total visits for physician-referred episodes in the Mitchell and de Lissovoy study and 77.1 percent of total visits in the Leemrijse et al. study. After adjusting for other factors, we found self-referred episodes to have 86.2 percent as many visits as physician-referred. One explanation for the higher percentage in our study is that we controlled for case mix.

Some PT episodes had only one PT visit - 21 percent of the self-referred and 16 percent of the physician-referred episodes. Of those episodes with two or more visits, the median length of the episode was 22 days (IQR 32 days) for self-referrals compared to 24 days (IQR 40) for physician referrals, which is consistent with the single visit difference in overall mean visits for the two groups.

The self-referred and physician-referred groups were quite similar on demographic and clinical characteristics, although the self-referred group was younger. Given that older individuals are more likely to have more comorbidities and, therefore, more physician visits in general, this is not surprising. While there were some differences in both PT use and non-PT claims (during the PT episode only) in the groups by diagnostic category, these were small. The proportion of individuals with spine conditions and sprain/strains who self-referred was slightly higher than the proportion who saw a physician, and the proportion of individuals with arthritis who self-referred was slightly lower. From a clinical perspective, these findings make sense as individuals with spine problems often deal with recurrence/flare-ups and sprains/strains are self-limiting and often treated with physical modalities and exercise. Arthritis, on the other hand, is often treated with medication, requiring ongoing physician management, in addition to PT and exercise.

One interesting finding was how similar the two groups were with respect to case mix, as measured by the 67 ACG categories (Figure A1; Table A4). Because of the operational definition of physician-referred, one might have expected that group to have substantially more persistent or serious medical conditions, or the self-referred group to be much less engaged in the health care system. This was not the case. Both referral groups were engaged with the health care system during their PT episode of care. During that time, 45.6 percent of the self-referred and 49.4 percent of the physicianreferred groups had at least one claim for a physician visit whose specialty type would have qualified them to be in the physician-referred group. However, the allowable amounts for related non-PT claims during the episode were higher in the physician group, indicating concurrent care for the same type of 
problem. In the 60 days after the PT episode, no differences were found between referral groups, despite the high power to find such.

Our findings suggest that the role of the physician gatekeeper in regard to PT may be unnecessary in many cases. Health care use did not increase in the self-referred group, nor was continuity of care hindered. The self-referred patients were still in contact with physicians during and after PT. Concerns about patient safety, missed diagnoses, and continuity of care for individuals who self-refer may be overstated.

This study extends previous research comparing physician-referred and self-referred PT episodes of care by examining both PT and non-PT related health care use before, during, and after the PT episode of care. We found that total allowable amounts for related health care claims before the PT episode were somewhat higher in the physician-referred group, with a difference of about $\$ 44$ more for men and $\$ 18$ for women. During the PT episode the total allowable amounts were also higher in the physicianreferred group with a difference of approximately $\$ 70$ more for females and $\$ 93$ more for males. There was no difference found in the two groups in the 60 days afterward.

While our findings indicate that a self-referred PT episode of care is less costly and shorter in duration than a physician-referred episode of care, we do not know whether this is indicative of greater efficiency for the selfreferred episode, greater illness severity, delayed access for the physicianreferred episode, or some combination of these factors. Although we controlled for diagnoses, comorbidities, and other patient characteristics, we were limited to the information available in claims data. We did not have any direct measures of functional status, nor were we able to assess whether quality and/or outcomes differed among the groups. We also could not definitively know whether the patient self-referred. Rather, we relied on a "new-user design" to assign referral status. Thus, it is still possible that patients who self-refer do so because they have less serious PT problems. Considering the limitations of our analyses, interpretations of differences in costs and visits should be made with caution. We believe our most relevant findings are that health care use was not greater for self-referred patients and that self-referred patients remain engaged with the health care system during the PT episode of care.

In summary, our findings do not support the assertion that self-referral leads to overuse of care or discontinuity in care, based on a very large population of individuals in a common private health insurance plan with no requirement for PT referral or prohibition on patient self-referral. We consistently 
found lower use in the self-referral group, after adjusting for key demographic variables, diagnosis group, and case mix. We also found that individuals in both groups were similarly engaged with the medical care system during their course of care and afterward.

\section{ACKNOWLEDGMENTS}

Joint Acknowledgment/Disclosure Statement: The authors appreciate the collaborative relationship between Wellmark, Inc. (dba as Wellmark Blue Cross and Blue Shield of Iowa and Wellmark Blue Cross Blue Shield of South Dakota) and the University of Iowa, which has created this secured, IRB-approved Data Repository, accessible without charge or censorship rights to University of Iowa faculty researchers. Authors J. Pendergast and S. Kliethermes received partial financial support for time spent analyzing the data from the American Physical Therapy Association (APTA), but they are not members of the APTA. J. Freburger received financial support for this study and is currently a volunteer member of the APTA's Health Policy/Workforce Task Force, is a past member of APTA's Research Advisory Board, and is funded by the APTA for another project unrelated to this one. P.A. Duffy has been an independent contractor or employee with Wellmark Blue Cross and Blue Shield of IA since 2000. She received no financial support for this study. None of the authors had any obligation to report or share study findings before publication, and the APTA was given no opportunity to read or comment on this manuscript. The views expressed here are those of the authors and do not necessarily represent those of Wellmark, Inc. or the American Physical Therapy Association. The authors thank Kendra Heatwole Shank for her assistance in the preparation of an earlier version of this manuscript.

Disclosures: None.

Disclaimers: None.

\section{NOTES}

1. There is no health plan requirement for physician referral or prohibition with self-referral for all covered members. The medical and payment guidelines for the beneficiaries are applied equally across both outpatient and hospital settings. Both states have full direct access, meaning that both evaluation and treatment are permitted by physical therapists without a referral from a physician. 
2. Physical therapists were identified in the Data Repository by a specialty code of 65 and provider type of 34 .

3. Aggregated Diagnostic Group is a grouping of diagnosis codes that are similar in terms of severity and likelihood of persistence of the health care condition over time.

\section{REFERENCES}

Agency for Healthcare Research and Quality (AHRQ). 2009a. "Clinical Classifications Software (CCS) for ICD-9-CM" [accessed on February 25, 2010]. Available at http://www.hcup-us.ahrq.gov/toolssoftware/ccs/ccs.jsp.

2009b. "MEPS HC-110F Codebook 2007 Outpatient Department Visits" [accessed on February 25, 2010]. Available at http://www.meps.ahrq.gov/mepsweb/data_stats/download_data/pufs/h110f/h110fcb.pdf.

—. 2009c. "MEPS HC-110G Codebook 2007 Office-based Medical Provider Visits" [accessed on February 26, 2010]. Available at http://www.meps.ahrq.gov/ mepsweb/data_stats/download_data/pufs/h110g/h110gcb.pdf.

American Physical Therapy Association. 2004. "Position on Principles and Objectives for the United States Health Care System and the Delivery of Physical Therapy Services HOD P06-04-17-16" [accessed on July 8, 2010]. Available at http:// www.apta.org/uploadedFiles/APTAorg/About_Us/Policies/HOD/Health/ Principles.pdf.

. 2011. "A Summary of Direct Access Language in State Physical Therapy Practice Acts: Direct Access to Physical Therapy Laws" [accessed on August 25, 2011]. Available at http://www.apta.org/uploadedFiles/APTAorg/Advocacy/ State/Issues/Direct_Access/DirectAccessbyState.pdf.

BlueCross BlueShield Association (BCBSA). 2011. "Healthcare Coverage Glossary" [accessed on February 17, 2011]. Available at http://www.bcbs.com/coverage/ glossary.

Childs, J. D., J. M. Whitman, P. S. Sizer, M. L. Pugia, T. W. Flynn, and A. Delitto. 2005. "A Description of Physical Therapists' Knowledge in Managing Musculoskeletal Conditions." BMC Musculoskeletal Disorders 6: 32.

Ciolek, D. E., and W. Hwang. 2008. Outpatient Therapy Alternative Payment Study 2 (OTAPS 2) Task Order; CY 2006 Outpatient Therapy Cap Report. Baltimore, MD: Computer Sciences Corporation.

Freburger, J. K., G. M. Holmes, and T. S. Carey. 2003. "Physician Referrals to Physical Therapy for the Treatment of Musculoskeletal Conditions." Archives of Physical Medicine and Rehabilitation 84 (12): 1839-49.

Iowa Code. 2010. "Title IV Public Health, Subtitle 3 Health-Related Professions, Chapter 148A Physical Therapy, Section 148A1 Definitions-referral - authorization" [accessed May 30, 2010]. Available at http://search.legis.state.ia.us/nxt/ gateway.dll/ar/iac?f=templates $\$ \mathrm{fn}=$ default.htm. 
The Johns Hopkins Bloomberg School of Public Health. 2008. The Johns Hopkins ACG ${ }^{\odot}$ System, Version 8.2, December 2008. Baltimore, MD. Available at http://acg. jhsph.edu.

Leemrijse, C. J., I. C. S. Swinkels, and C. Veenhof. 2008. "Direct Access to Physical Therapy in the Netherlands: Results from the First Year in Community-Based Physical Therapy." Physical Therapy 88 (8): 936-46.

Martin, B. I., R. A. Deyo, S. K. Mirza, J. A. Turner, B. A. Comstock, W. Hollingworth, and S. D. Sullivan. 2008. "Expenditures and Health Status among Adults with Back and Neck Problems." Journal of the American Medical Association 299 (6): 656-64.

Medicare Payment Advisory Commission. 2004. Glenn M. Hackbarth, Chairman. Letter to the Honorable Richard Cheney on Direct Access to Outpatient Physical Therapy Services, Dated December 30. Washington, DC: MedPAC [accessed May 30, 2010]. Available at http://www.medpac.gov/publications/congressional_ reports/Dec04_PTaccess.pdf.

Mirabito, A. M., and L. L. Berry. 2010. "Lessons That Patient-Centered Medical Homes Can Learn from the Mistakes of HMOs." Annals of Internal Medicine 152 (3): 182-6.

Mitchell, J. M., and G. de Lissovoy. 1997. "A Comparison of Resource Use and Cost in Direct Access Versus Physician Referral Episodes of Physical Therapy.” Physical Therapy 77 (1): 10-18.

Moore, J. H., D. L. Goss, R. E. Baxter, T. M. DeBerardino, L. T. Mansfield, D. W. Fellows, and D. C. Taylor. 2005a. "Clinical Diagnostic Accuracy and Magnetic Resonance Imaging of Patients Referred by Physical Therapists, Orthopaedic Surgeons, and Nonorthopaedic Providers." Journal of Orthopaedic E Sports Physical Therapy 35 (2): 67-71.

Moore, J. H., D. J. McMillian, M. D. Rosenthal, and M. D. Weishaar. 2005b. "Risk Determination for Patients with Direct Access to Physical Therapy in Military Health Care Facilities." Journal of Orthopaedic E Sports Physical Therapy 35 (10): 674-8.

Miller, R. H., and H. S. Luft. 2002. "HMO Plan Performance Update: An Analysis of the Literature, 1997-2001." Health Affairs 21 (4): 63-86.

Overman, S. S., J. W. Larson, D. A. Dickstein, and P. H. Rockey. 1988. "Physical Therapy Care for Low Back Pain. Monitored Program of First-Contact Nonphysician Care." Physical Therapy 68 (2): 199-207.

South Dakota Codified Laws. 2010. Title 36, Chapter 10, Section 18.1 [accessed May 12, 2010]. Available at http://legis.state.sd.us/statutes/DisplayStatute.aspx? Statute $=36019-18.1 \&$ Type $=$ Statute.

Springer, B. A., R. A. Arciero, J. J. Tenuta, and D. C. Taylor. 2000. "A Prospective Study of Modified Ottawa Ankle Rules in a Military Population." American Journal of Sports Medicine 28 (6): 864-8. 


\section{SUPPORTING INFORMATION}

Additional supporting information may be found in the online version of this article:

Appendix SA1: Author Matrix.

Table A1: Diagnostic Category CCS Codes and Definitions.

Table A2: Physician Specialties Used to Classify Physician-Referred Episodes.

Table A3: All Possible ACG Categories in The Johns Hopkins ACG System (Version 8.2).

Table A4: Largest Differences Observed in ACG Categories between the Two Referral Groups.

Table A5: Number of PT Visits: Joint Likelihood Ratio Tests of Model Predictors.

Table A6: Least Squares Means for Number of PT Visits, Adjusted for All Other Predictors.

Table A7: $\log _{\mathrm{e}}$ (Allowable Amounts) 30 Days Prior PT Episode: Joint Likelihood Ratio Tests of Model Predictors.

Table A8: Least Squares Means of Related Allowable Amounts 30 Days Prior to PT Episode.

Table A9: $\log _{\mathrm{e}}$ (Allowable Amounts) of PT Claims in the PT Episode Only: Joint Likelihood Ratio Tests of Model Predictors.

Table A10: Least Squares Mean Comparisons of Allowable Amounts of PT Claims in the PT Episode.

Table A11: Related Claim $\log _{\mathrm{e}}$ (Allowable Amounts) during PT Episode: Joint Likelihood Ratio Tests of Model Predictors.

Table A12: Least Squares Means of Related Claim Allowable Amounts During PT Episode.

Table A13: $\log _{\mathrm{e}}$ (Allowable Amounts) 60 Days Post PT Episode: Joint Likelihood Ratio Tests of Model Predictors.

Table A14: Least Squares Means of Related Allowable Amounts 60 Days Post PT Episode.

Figure A1: Comparison of ACG Categories between Self-Referred and Physician-Referred Patients.

Please note: Wiley-Blackwell is not responsible for the content or functionality of any supporting materials supplied by the authors. Any queries (other than missing material) should be directed to the corresponding author for the article. 